\title{
Analysis of a Policy in Health Care: A Case of Australia's Anti-Smoking Policy
}

\author{
Yoshiyuki Nagaya* \\ Kansai University of Social Welfare, Japan
}

Received: May 29, 2018; Published: June 08, 2018

*Corresponding author: Yoshiyuki Nagaya, Kansai University of Social Welfare, 380-3 Shinden, Ako, Hyogo 678-0255 Japan

\section{Introduction}

Since at least the late 1960's, the Australian Government has combined a range of different anti-smoking policies in its effort to combat smoking. Efforts such as advertising and promotion restrictions (for example, point of sale limitations), packaging and labeling laws, excise or taxation of tobacco and public and workplace bans have all been used in an attempt to lower smoking levels among the Australian population [1]. First enacted in 2012, the plain packaging laws are intended to reduce smoking addiction in Australia even further. The legislation aims to make cigarette packets even less appealing, resulting in their lower consumption. It is important to note, however, that plain packaging is just one of the many measures presently being used to lower smoking levels in
Australia. Other measures too also need to be used, in combination, to reduce smoking in Australia. The Government's pre-occupation with anti-smoking policies is not surprising given that smoking still continues to be one of the most significant factors contributing to serious illness for Australians, causing death to more than 15,000 people annually. The economic, health and societal impact of smoking costs over $\$ 30$ billion annually. Over three million Australians still smoke, despite a fall of 500,000 daily smokers over the last ten years [2].Approximately $17.5 \%$ of males and $14.5 \%$ of females over 18 view themselves as daily smokers [3]. (Table 1 ) shows a detailed breakdown of the prevalence of smoking among men and women in Australia in 2010.

Table 1: Breakdown of smoking patterns for Australian men and women by age (2010).

\begin{tabular}{|c|c|c|c|}
\hline Smoking status & Males & Females & Persons (males \& females) \\
\hline Daily & 17.4 & 14.5 & 1.6 \\
\hline Weekly & 1.9 & 1.2 & 17.5 \\
\hline Total regular smokers (daily plus weekly) & 19.3 & 15.7 & 1.5 \\
\hline Less than weekly & 1.7 & 1.2 & 19 \\
\hline $\begin{array}{c}\text { Total current smokers (daily, weekly, less than } \\
\text { weekly) }\end{array}$ & 21 & 16.9 & 25.6 \\
\hline Ex-Smokers(a) & 28.2 & 23.1 & 55.4 \\
\hline
\end{tabular}

Note: (a)Smoked at least 100 cigarettes or the equivalent amount of tobacco in their life and reports no longer smoking.

(b)Never smoked more than 100 cigarettes or the equivalent amount of tobacco

\section{Impetus for Introduction of Policy}

Like all anti-smoking policies introduced over the years, Aus tralia's plain packaging laws were enacted in an effort to reduce smoking and its detrimental impacts in the community. The laws were enacted out of a concern that the message that smoking kills is still not proving successful, despite repeated attempts to reinforce this message over the years [4]. Smokers are still either lacking in formation or ignoring the information about the health effects of smoking on them [5]. The Government therefore perceived that a more drastic measure was required to address smoking.The Government's overall aim is to lower Australia's smoking rate to just ten percent of the population by 2018 and reduce by $50 \%$ the smoking rate among the indigenous population.Plain packaging is just one element of the Government's efforts to lower smoking, removing what is effectively the only type of tobacco advertising left on packs [6]. The Government's other key policies designed to 
combat smoking include the $25 \%$ excise rise enacted in 2010, media campaigns and laws which limit tobacco ads on the web [7]. Another reason for Australia's plain packaging laws is the overall trend in consumers' behaviour patterns, in response to legal change. Figure 1 shows how tobacco packs, in Australia, have changed over the years, with health warnings and graphics becoming more sizeable. From left to right: a) 1987 to 1994; b) 1995 to 2005; c) 2006 to 2012; d) after plain packaging laws Interestingly, over the same period that cigarette packs have changed, the overall prevalence of daily smokers has fallen in almost every age group in the Australian community [3]. Figure 2 shows this trend.

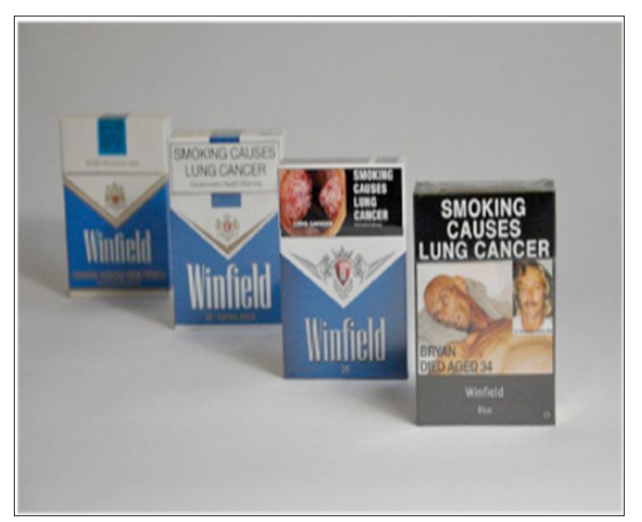

Figure 1: History of health warnings in Australia.

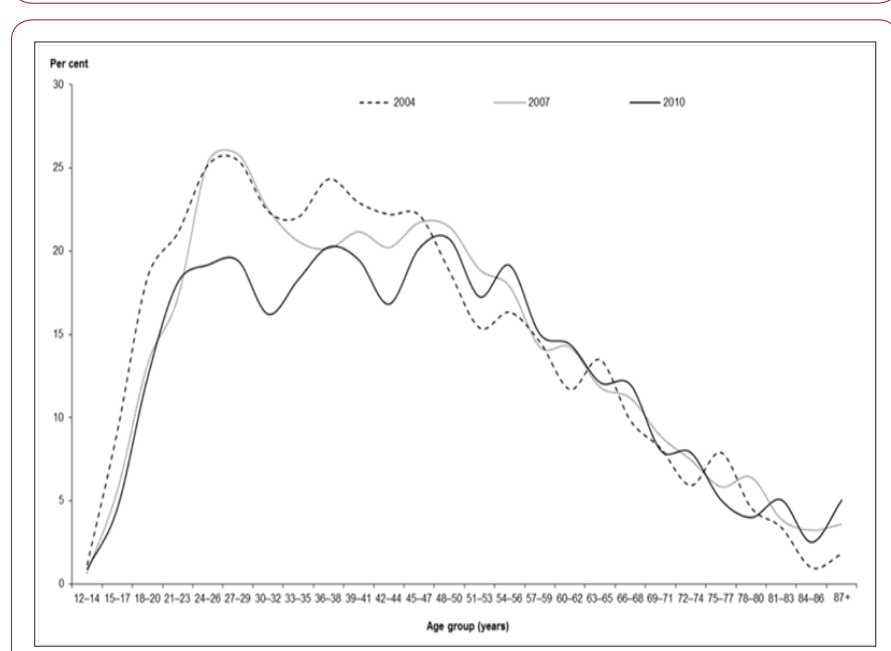

Figure 2: Historical pattern of daily smokers in Australia by age group (2004, 2007 and 2010).

\section{Implementation of Policy}

Like most anti-smoking policies, the Government's plain packaging policy was developed and implemented through legislation by the Australian Federal Government. The first step to the implementation of the policy was a decision by Federal Parliament to pass legislation regarding plain packaging. The law enacting plain packaging was the Tobacco Plain Packaging Act (2011) [8,9]. In short, the Act limits various elements of tobacco packaging, including, most importantly the appearance of trademarks on packs [10]. Once legislation has been enacted by Parliament, penalties will follow from a failure of smoking suppliers to comply. The punishment that results from the enactment of Act is a critical aspect to the implementation of the anti-smoking policy. Before taking effect, however, the plain packaging law was challenged by tobacco suppliers in the High Court. The tobacco suppliers argued that the Government was seeking to buy the supplier's trademarks for too low a price. The Government submitted that it was just seeking to legislate the appearance of cigarette boxes, rather than acquiring any trademarks. Luckily for Australia, the High Court upheld plain packaging [11]. Now tobacco suppliers may face significant penalties if they do not obey the law. Bad publicity for suppliers that breach the laws will also result. Together bad publicity and punishment encourages suppliers to comply with the law. Another aspect of the implementation of the policy is the exposure of the public to plain packs. This is probably the most significant element of the policy's implementation. The public by being exposed to the newly designed tobacco packs, is affected, which in turn should translate to a change in behavior relating to the consumption of tobacco in practice. Historically, this has been found to be the outcome.

\section{Key Stakeholders}

Anti-smoking policy in Australia, as in most countries, concerns various key stakeholders, including the Government, smokers and non-smokers, health professionals and tobacco suppliers and their representative bodies (for example, the Tobacco Institute of Australia) [12]. Initially, smoking has health consequences for the individuals who smoke. Then, it costs the Government by health resources being devoted to smokers, instead of other individuals. Non-smokers are impacted through passive (or second-hand) and perhaps even third-hand smoking [13] and the significant costs of tobacco consumption by smokers who may be part of their family. Costs to the health industry are also significant [1]. Smokers may oppose measures to decrease tobacco consumption. Measures likely to raise the price of tobacco, in particular, are likely to prove unpopular. This is because once addicted, it may be difficult for tobacco smokers to give up their addiction. Tobacco generally tends to be price inelastic. The Government may therefore be reluctant to increase the price of tobacco to significant levels due to the unpopularity of price hikes, this is why measures relating to advertising, labeling and packaging often become a preferred option to the additional taxation of tobacco. It is better to sway individuals to give up smoking, not because of its price, but for other reasons. Smoking also impacts people from different backgrounds differently, making it a controversial issue for the Government. Smoking then becomes an issue of social equality [1].

People from lower socioeconomic backgrounds, the mentally ill and certain ethnic communities all experience higher smoking rates than others. Indigenous Australians too have much higher smoking rates than the rest of the population [2]. Due to the varying impact of smoking in the community, the Government is likely to have a significant interest in ensuring that smoking is addressed. Social and political instability may result if the Government does not devise and implement effective anti-smoking policies. Non-smokers are another key stakeholder in the debate. Non-smokers may have ambivalent reactions to anti-smoking policies. Non-smokers, like smokers, are not a homogenous group. Some non-smokers may live with and relate to smokers, thus measures aimed at reducing smoking may not appease them. They may sympathise with smokers particularly when the price of cigarettes rises. By contrast, those non-smokers who are concerned with the health implications of 
smoking to themselves and to others may be strongly in favour of all measures against smoking.

The tobacco industry naturally has a great interest in ensuring the liberalisation of the supply of tobacco. Any form of regulation of tobacco may potentially lead to a reduction in the market and profitability of tobacco and cigarette products [5]. Any measure, particularly one which may prove effective is therefore likely to be sternly opposed by tobacco suppliers and its representative bodies.When introducing policies directed at reducing smoking levels therefore the Government needs to balance these competing interests and develop a policy which can be introduced without too much backlash from voters. This has been coined as the smoking 'tug-of-war' [1]. It is against this backdrop of conflicting views and opinions on the subject-matter that all anti-smoking policies must be analysed, including the relatively recently introduced plain packaging laws.

\section{Evidence on Policy}

Despite its infancy, there is an overwhelming body of research, evidence and studies supporting the positive effects of plain packaging. In particular, research suggests that the removal of brand information from tobacco packs lowers positive cigarette brand image associations among adolescents $[14,15]$. Also, addiction to smoking is decreased by the size of pictorial health warnings [16]. Plain packaging may therefore lead to cessation-related behaviour.

\section{Evidence also Indicates That Plain Packs:}

a) are usually seen as less appealing than branded packets, both by adults and youth;

b) are viewed as of inferior quality to branded packets discouraging individuals from consuming cigarettes;

c) are seen as uncool, unfashionable and as consumed by 'older' people than branded packs;

d) are perceived as detrimental for a person's health and usually have negative feelings associated with them [17];

e) depict a lessattractive smoker persona and reduce the overall experience;

f) increase the prominence of health warnings and make them more serious and believable, reducing the uptake and cessation of cigarette smoking [14s,18-20];

g) more clearly expose the reality of smoking and reduce the health beliefs associated with smoking [20];

h) are less likely than packs showing branding to lead women to believing that smoking assists in weight control [20]; and

i) Affect an individual's social persona, irrespective of gender and ethnicity.

Together this evidence suggests that plain packaging laws may cause a reduction in tobacco consumption, particularly when implemented together with other types of anti-smoking policies [21]. To some extent, the above evidence also provided the basis for en- acting of Australia's plain packaging rules [7]. It may be, however, that further research needs to be undertaken into the actual colours chosen for packages. Brown may be viewed as natural due to its recycling connotation. White too may be seen as associated with lower harm. The Australian Government is therefore considering changing the background colour to a dark olive green color. It may still be early days, however, to rely on the positive findings of the evidence. Problems may exist with the evidence. For instance, the impact of plain packing on different types of smokers may vary and these issues need to be the subject of additional consideration to assess whether alternative measures may be more effective.

Heavy and light smokers, for instance, may respond differently to plain packaging [20]. Anti-smoking policies generally operate together to produce an overall result, making it difficult or impossible to measure their independent contribution. It is clear that in the anti-smoking area, no single measure alone can prove effective as a solution. Improved modeling methods, particularly those that allow for an examination of the impact of different policies may be necessary. Anti-smoking policies need to be considered, taking into account the various price and non-price policies developed by the Government, in assessing the success or failure of any particular policy [22].

\section{Perspectives on Policy}

Different perspectives also need to be examined and analysed when introducing anti-smoking policies. Issues raised by the tobacco industry, while somewhat unpopular among Governments and non-smokers alike, need to be assessed. Plain packaging has been opposed by the tobacco industry on the basis that it will result in criminal groups selling illegal tobacco. A black market for tobacco may arise if cigarette packs all look identical and they are easy to copy [11]. Another attack by the tobacco industry on plain packaging is that the black market will make it more costly for the Government to collect excise duty in the ordinary legal market. The tobacco industry also states that plain packaging may lead to a lower cost of legal tobacco.Without branding tobacco companies will need to compete based on price. In turn, price competition may result in youth having the opportunity to buy tobacco. Plain packaging may reduce the price of tobacco anyway since branding may actually increase the cost of tobacco. Plain packaging may undermine the perceived difference between cigarettes and other products which are not detrimental to health. Plain packaging could also raise the attractiveness of smoking by youth because of being seen to be 'forbidden' or 'dangerous' [20]. Transaction costs associated with the sale of plain packs may also be higher. The extent to which this cost is real, however, has been questioned by some authors [23].

\section{Conclusion}

Australia's plain packaging laws introduced in 2012, were the first of their kind in the world.As a pioneer in anti-smoking policies throughout history, this is unsurprising. It remains to be seen whether or not the policy will prove effective in reducing or combating smoking. The evidence in support of the policy, however, seems overwhelming. Potentially though, the most effective policy to combat smoking may be to make cigarettes exorbitantly costly 
and inaccessible to most of the general public. If cigarettes are converted to a luxury good, through higher excise duty, many in the community may find cigarettes unaffordable and turn away from their consumption. This may have a substantial and real effect in reducing tobacco consumption in Australia. It is difficult, however, for the smoking community and the tobacco industry to accept such efforts. Governments have therefore steered away from such a policy in favour of less direct efforts to reduce consumption of smoking. It remains to be seen, whether in the medium to long term, such efforts will have the substantial effect on changing smoking behaviour and hence lower the rate of smoking in Australia to a level acceptable to the community. Given the historical patterns resulting from legislative change, under various anti-smoking policies, however, the Government should be optimistic about the likely effects of plain packaging on changing consumer behaviour.

\section{References}

1. Scollo M, Winstanley M (2012) Tobacco in Australia: facts and issues. ( $4^{\text {th }}$ Edn.). In: Scollo M, Winstanley M, (Eds.). Cancer Council Victoria, Melbourne.

2. Kerryn Riseley (2003) Repot on smoke-free policies in Australia. DHS, Melbourne.

3. (2011) Australian Institute of Health and Welfare 2011, National Drug Strategy Household Survey 2016 Canberra.

4. Olson S (2013) Australia's anti-smoking campaign threatens global success of tobacco industry: WTO legal battle continues. New York, USA.

5. Hammond D, Fong G, McNeill A, Borland R, Cummings K (2006) Effectiveness of cigarette warning labels in informing smokers about the risks of smoking: findings from the international tobacco control (ITC) four country survey. Tobacco Control 15(3): 19-25.

6. Hoek J, GendallP, Gifford H, Pirikahu G, McCool J, et al. (2012) Tobacco branding, plain packaging, pictorial warnings, and symbolic consumption. Qualitative Health Research 22(5): 630-639.

7. Australian Government (2011) Tobacco plain packaging Act 2011.

8. Quit Victoria (2014) Plain packaging. QVviewed 1-6-2017 Melbourne.
9. (2011) Australian Government 2011, Tobacco plain packaging Act 2011.

10. (2012) JT International SA v. Commonwealth of Australia 2012, HCA 43.

11. (2012) Australian Broadcasting Corporation (2012) High Court rejects plain packaging challenge. $\mathrm{ABC}$, Ultimo.

12. Palmer G, Short S (2010) Health care and public policy: an Australian analysis.(4th edn) In Palmer G, Short S, Palgrave Macmillan, Melbourne.

13. Ballantyne C (2009) What is third-hand smoke? Is it dangerous? Scientific American 9: 130.

14. Hoek J, Wong C, Gendall P, Louviere J, Cong K (2011) Effects of dissuasive packaging on young adult smokers. Tobacco Control 20(3): 183-188.

15. Wakefield M, Germain D, Durkin S (2008) How does increasingly plainer cigarette packaging influence adult smokers' perceptions about brand image? An experimental study. Tobacco Control 17(6): 416-421.

16. Germain D, Wakefield M, Durkin S (2010) Adolescents' perceptions of cigarette brand image: does plain packaging make a difference? Journal of Adolescent Health46(4): 385-392.

17. Dewhirst T, Davis B (2005) Brand strategy and integrated marketing communication. Journal of Advertising 34(4): 81-92.

18. Hammond D, Parkinson C(2009) The impact of cigarette package design on perceptions of risk. Journal of Public Health31(3): 345-353.

19. MunafòM, Roberts N, Bauld L, Leonards U (2011) Plain packaging increases visual attention to health warnings on cigarette packs in nonsmokers and weekly smokers but not daily smokers Addiction 106(8): 1505-1510.

20. Moodie Crawford, Stead Martine, Bauld Linda, McNeill Ann, Angus Kathryn, et al. (2012) Plain tobacco packaging: a systematic review University of Stirling US, Scotland.

21. Hammond D (2011) Health warning messages on tobacco products: a review, Tobacco Control. 20: 327-337.

22. Goel R, Nelson M (2006) The effectiveness of anti-smoking legislation: a review, Journal of Economic Surveys. 20(3): 325-355.

23. Gittins R (2012) Big tobacco - what have they been smoking? SMH, Sydney, Australia.

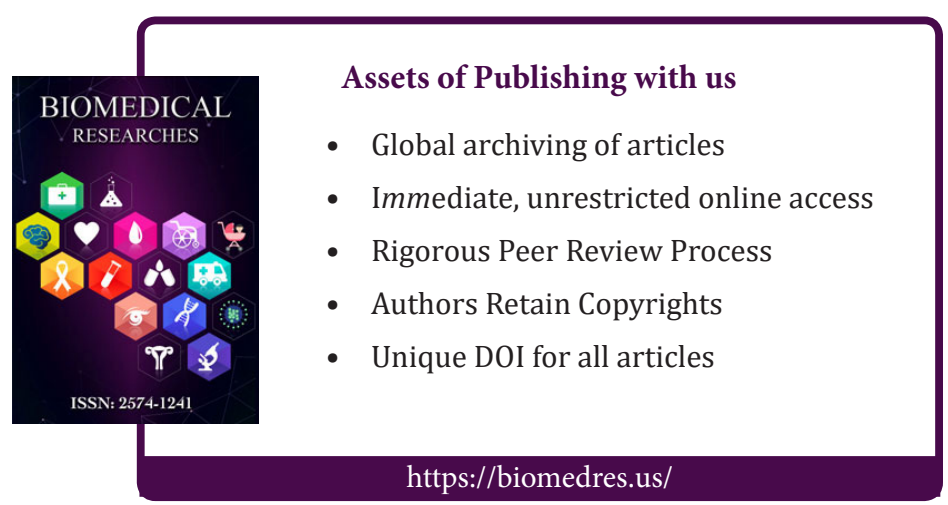

